\title{
PROFESSORES DE LÍNGUA PORTUGUESA E MÍDIA IMPRESSA: INSERÇÃO DAS NOVAS TICS NA EDUCAÇÃO
}

\author{
(Teachers of portuguese language and print media: \\ insertion of new ICT in Education)
}

\author{
Maria Aparecida Resende Ottoni ${ }^{1}$ \\ Flávia Motta de Paula
}

(Universidade Federal de Uberlândia - UFU)

\begin{abstract}
This article presents an analysis of a report in the magazine New School and two interviews with teachers of municipal schools in Uberlândia. The aim is to investigate how the print media and teachers discursively represent the integration of information and communication technologies (ICTs) in education. For this, we adopt the assumptions of Critical Discourse Analysis (FAIRCLOUGH, 2001, 2003). The results show that the lexical choices in the present report contributes to building a positive representation of the integration of ICTs in education and to affirm the need for such integration. In the discourse of the teachers noticed that the new ICTs are fruitful for education, however, some factors prevents the current use.
\end{abstract}

Keywords: information and communication technology; critical discourse analysis; media; discourse of the teachers.

\section{RESUMO}

Neste artigo, apresentamos a análise de uma reportagem da revista Nova Escola e de duas entrevistas com professoras da rede municipal de ensino de Uberlândia. O objetivo é investigar como a mídia impressa e professores

1. Doutora em Linguística pela Universidade de Brasília. Docente dos cursos de Letras e de Comunicação Social com habilitação em Jornalismo, da Universidade Federal de Uberlândia.

2. Discente do Programa de Pós-Graduação em Estudos Linguísticos (PPGEL), Curso de Mestrado, do Instituto de Letras e Linguística, da Universidade Federal de Uberlândia (UFU). Bolsista CAPES. 
representam discursivamente a inserção das tecnologias da informação e comunicação (TICs) na educação. Para isso, adotamos os pressupostos da Análise de Discurso Crítica (FAIRCLOUGH, 2001, 2003). Os resultados mostram que as escolhas lexicais presentes na reportagem contribuem para a construção de uma representação positiva da inserção das novas TICs na educação e para a afirmação da necessidade dessa inserção. No discurso das professoras percebemos que as novas TICs são proficuas para a educação, porém, alguns fatores impedem a utilização corrente.

Palavras-chave: tecnologia da informação e comunicação; análise de discurso crítica; mídia, discurso docente.

\section{Introdução}

Abordamos, neste artigo ${ }^{3}$, os resultados de nossa pesquisa sobre a análise do discurso da mídia impressa e de professores de Língua Portuguesa, da educação básica, da cidade de Uberlândia. Objetivamos discutir e analisar como a mídia impressa e professores representam discursivamente a inserção das Novas Tecnologias da Informação e Comunicação (TICs) na educação.

O corpus do estudo é constituído por três reportagens da revista Nova Escola - uma das revistas de maior circulação entre os educadores da Educação Básica - e três entrevistas. Centramo-nos, neste recorte, na análise de uma reportagem intitulada como "A tecnologia que ajuda a ensinar", de Amanda Polato, publicada em junho/julho de 2009, e na análise de duas entrevistas.

A escolha da revista deve-se ao fato de que ela é considerada fonte de informação legítima por boa parte dos educadores. Eles recorrem a ela para saber o que há de mais atual na área e para buscar

3. Este artigo é parte integrante de nossa pesquisa que foi desenvolvida com o objetivo de investigar e discutir a representação discursiva da inserção das novas Tecnologias de Informação e Comunicação (TICs) na educação, construída na e pela revista Nova Escola e no discurso de professoras da Língua Portuguesa de escolas da rede pública. 
subsídios para a prática pedagógica. Assim sendo, entendemos que as representações construídas nessa revista podem influenciar na representação de mundo construída pelos professores leitores e na constituição identitária desses sujeitos.

Para realização das entrevistas, primeiramente, foram selecionadas duas escolas municipais, as quais estão inseridas em um projeto da Prefeitura Municipal, conhecido como "Digitando o futuro", implantando em 1995, o qual previa que todas as escolas municipais estariam equipadas com computadores e internet com banda larga até 2010.

Para a seleção dos entrevistados, seguimos os seguintes critérios: a) lecionar há pelo menos 02 anos na mesma escola; b) trabalhar com a Língua Portuguesa no ensino fundamental; c) aceitar participar da pesquisa.

As entrevistas foram profícuas para investigar se professores de Língua Portuguesa do $3^{\circ}$ ciclo do Ensino Fundamental de escolas da rede pública equipadas com as TICs utilizam-nas, como e por que e também analisar como esses professores de Língua Portuguesa representam discursivamente a inserção das TICs na educação e os efeitos dessa inserção na constituição identitária desses docentes. Para as análises, apoiamo-nos em documentos oficiais como os Parâmetros Curriculares Nacionais (PCN) e em diversos estudos que têm sido produzidos acerca da inserção das novas TICs na educação e adotamos os pressupostos teóricos da Análise de Discurso Crítica (ADC) (FAIRCLOUGH, 2001, 2003), sobre o que discorremos no próximo tópico.

Para exposição de parte dos resultados desta pesquisa, organizamos este artigo em 03 (três) partes, além da introdução. $\mathrm{Na}$ primeira, apresentamos os pressupostos da Análise de Discurso Crítica. Na segunda, discorremos sobre a inserção das tecnologias da informação e da comunicação (TICs) e, na terceira, apresentamos as análises dos dados. Por último, fazemos uma conclusão do trabalho, retomando o caminho percorrido e sintetizando os resultados da investigação. 


\section{A Análise de Discurso Crítica}

A Análise de Discurso Crítica (ADC) é uma ciência que tem como objeto de estudo o social e se volta para a análise das relações dialéticas entre o discurso (incluindo a linguagem verbal e as outras formas de semiose) e outros elementos das práticas sociais (ação e interação, relações sociais, pessoas com crenças, atitudes, histórias etc., o mundo material). Preocupa-se com as mudanças radicais que estão ocorrendo na vida social contemporânea, com o modo como o discurso figura dentro dos processos de mudança e com as transformações na relação entre o discurso/semiose e outros elementos sociais dentro das redes de práticas (OTTONI, 2007).

O conceito de discurso utilizado nesta pesquisa parte da proposta de Fairclough (2001, p. 91), cuja explicação cabe registrar:

Ao usar o termo 'discurso', proponho considerar o uso da linguagem como forma de prática social e não como atividade puramente individual ou reflexo de variáveis institucionais. Isso tem várias implicações. Primeiro, implica ser o discurso um modo de ação, uma forma em que as pessoas podem agir sobre o mundo e especialmente sobre os outros, como também um modo de representação (...) Segundo, implica uma relação dialética entre o discurso e a estrutura social, existindo mais geralmente tal relação entre a prática social e a estrutura social: a última é tanto uma condição como um efeito da primeira.

A ADC propõe um diálogo entre a Ciência Social Crítica e a Linguística, especificamente a Linguística Sistêmico-Funcional (LSF). Fairclough (2003) associa a ideia de multifuncionalidade dos textos à distinção entre gêneros, discursos e estilos e aos três modos principais pelos quais o discurso figura como uma parte da prática social: modos de agir, modos de representar, modos de ser. $\mathrm{O}$ autor propõe três tipos de significados: o significado acional, o significado representacional e o significado identificacional, os quais estão co-presentes nos textos como acontece com as macrofunções apresentadas por Halliday (1994, 1997) e por Halliday e Hasan (1989). 
Fairclough (2003) relaciona o significado acional a gêneros/ modos de agir e à função interpessoal de Halliday (1994,1997). O significado representacional relaciona-se ao conceito de discurso como modo de representação de aspectos do mundo, correspondente à função ideacional. Já o significado identificacional é relacionado aos estilos/modos de ser. Nas palavras de Resende \& Ramalho (2006, p. 76), "estilos constituem o aspecto discursivo de identidades, ou seja, relacionam-se à identificação de atores sociais em textos".

Como em nosso estudo não utilizamos categorias referentes ao significado acional, abordaremos apenas os conceitos relativos aos significados representacional e identificacional. Mas é importante ressaltar que os significados acional, representacional e identificacional aparecem interligados, assim, "a distinção entre os três aspectos do significado é analítica, mas não exclui a fluidez e a internalização entre eles" (RESENDE, 2005, p. 40).

Fairclough (2003) relaciona significado representacional ao conceito de discurso como representação de diferentes aspectos do mundo. O autor nos mostra que diferentes discursos constroem diferentes maneiras de se representar diferentes perspectivas mundo. Segundo ele, um texto pode misturar diferentes discursos, os quais podem se complementar, podem cooperar uns com os outros, competir uns com os outros, dominar os outros. Assim, são estabelecidas relações dialógicas e/ou polêmicas pelos textos entre seus 'próprios' discursos e os discursos dos outros (FAIRCLOUGH, 2003, p. 128).

A identificação desses discursos articulados e da forma como são articulados em um texto constitui a análise interdiscursiva de um texto. A interdiscursividade ${ }^{4}$ diz respeito à heterogeneidade de um texto em termos da articulação de diferentes discursos. Ela é uma das categorias de análise do significado representacional utilizadas nesta pesquisa. De acordo com Fairclough (2003), os discursos são caracterizados e diferenciados não só pelo vocabulário e pelas relações semânticas e

4. Em Fairclough (2001) e também no glossário presente na obra de 2003, a interdiscursividade também é relacionada à articulação de outros elementos de ordens de discurso, como os gêneros e estilos. Porém, nesta pesquisa, ela será examinada apenas com relação à articulação de diferentes discursos. 
pressuposições, mas também pelos traços gramaticais. Eles diferem em como os elementos dos eventos sociais (processos, pessoas, objetos, meios, tempo, espaço) são representados e tais diferenças podem ser gramaticais e lexicais (vocabulário). O mais evidente dos traços distintivos de um discurso é o vocabulário, pois os discursos 'lexicalizam' o mundo de maneiras diferentes (FAIRCLOUGH, 2003, p. 129).

A análise interdiscursiva é profícua para esta pesquisa, pois nos possibilitará investigar quais discursos se articulam na composição do discurso da mídia impressa, especificamente da revista Nova Escola. Da mesma forma, a análise do vocabulário utilizado permitirá identificar como essa inserção é representada discursivamente nessa mídia.

Quanto ao significado identificacional, Fairclough (2003) relaciona-o diretamente ao conceito de estilo, que corresponde ao aspecto discursivo das identidades, dos modos de ser. Ele considera que o que as pessoas colocam nos textos é um importante indício de como se autoidentificam na 'texturização' das identidades. O autor afirma que as identidades, tanto social, como pessoal, acontecem por meio de diferentes traços linguísticos: "fonológico (pronúncia, entonação, ritmo), vocabulário e metáfora e por meio da interação entre a linguagem verbal e corporal (expressão facial, gestos, postura, estilo de roupa e cabelo)" como esclarece Ottoni (2007, p. 50). Além desses traços linguísticos, existem duas categorias relacionadas ao significado identificacional que são úteis especialmente para a análise a que nos propomos realizar: a avaliação e a modalidade.

A avaliação e a modalidade fazem parte das questões de análise textual, ligadas à função interpessoal, que Fairclough (2003) relaciona ao significado identificacional. A modalidade e a avaliação, segundo o referido linguista britânico, dizem respeito a como os autores se comprometem com eles mesmos em relação ao que é 'verdade' e ao que é necessário (modalidade) e, ainda, em relação ao que é desejável ou não, bom ou ruim (avaliação). As duas categorias são vistas em termos do comprometimento dos autores com o que é dito no texto, da sua avaliação sobre a validade ou verdade do que é declarado (modalidade), das atitudes, emoções, valores e julgamentos expressos, como ser desejável ou indesejável. 
Maria Aparecida Resende Ottoni e Flávia Motta de Paula

Portanto, para este estudo, destacaremos os significados representacional e identificacional da proposta de Fairclough (2003).

\section{A inserção das novas TICs na educação}

O Ministério da Educação tem apresentado diversas propostas para promover a inclusão digital na rede pública de ensino, como o Proinfo - Programa Nacional de Informática na Educação, UCA - Um computador por Aluno, TV Escola - um canal de televisão do MEC que capacita, aperfeiçoa e atualiza educadores da rede pública, Mídias na Educação - programa que visa proporcionar formação continuada para uso pedagógico das diferentes TICs (Tecnologias da Informação e Comunicação).

Da mesma forma, os Parâmetros Curriculares Nacionais, tanto do Ensino Fundamental quanto do Ensino Médio, argumentam em favor da educação das crianças e jovens para a recepção dos meios de informação e comunicação. Uma das características dos PCN apresentada na Introdução aos Parâmetros Curriculares Nacionais (BRASIL, 1998a, p. 11) é: "apontar a necessidade do desenvolvimento de trabalhos que contemplem o uso das tecnologias da comunicação e da informação, para que todos, alunos e professores, possam delas se apropriar e participar, bem como criticá-las e/ou delas usufruir". Nesse mesmo documento, uma parte é destinada ao tratamento das novas TICs, na qual é feita uma análise sobre o uso dessas tecnologias. Igualmente, nos PCN do Ensino Fundamental (BRASIL, 1998b), há um item destinado à abordagem das "Tecnologias da Informação e Língua Portuguesa”, no qual são tecidas considerações sobre o uso do computador, CD-Rom, multimídia e hipertexto, o rádio, a televisão e o vídeo no desenvolvimento do trabalho de leitura e produção de textos.

Nos diferentes documentos oficiais do Ministério da Educação, assim como nas propostas para promoção da inclusão digital, são apresentadas inúmeras vantagens decorrentes da utilização das novas TICs na educação, como: "gerar situações de aprendizagem com 
maior qualidade, ou seja, para criar ambientes de aprendizagem em que a problematização, a atividade reflexiva, atitude crítica, capacidade decisória e a autonomia sejam privilegiados” (BRASIL, 1998a, p. 141). Porém, nesses mesmos documentos, são também elencados diferentes fatores que contribuem para que a potencialidade das novas TICs ainda não seja reconhecida por muitos da comunidade nacional de educadores. Dentre eles, citamos: pouco conhecimento e domínio, por parte dos professores, para utilizar os recursos tecnológicos; ausência de equipamentos em muitas escolas; falta de condições para utilização dos equipamentos disponíveis e insuficiência de recursos financeiros para manutenção de equipamentos e para capacitação dos professores (BRASIL, 1998a, p. 142).

O Ministério da Educação, já em 1998, explicitava a necessidade de mudar essa realidade em curto espaço de tempo, em virtude da necessidade de a escola acompanhar os processos de transformação da sociedade, atendendo às novas demandas. E, com a publicação das propostas governamentais, cada vez mais se tem afirmado a necessidade e a relevância de se utilizar as novas TICs nos diferentes níveis de ensino e, cada vez mais, o professor de Língua Portuguesa e das outras áreas do conhecimento é "convidado" a inserir essas novas tecnologias na sua prática pedagógica.

A autora Belloni (2001, p. 10) propõe um objetivo fundamental para o estudo da inserção das novas TICs na educação, cujo comentário cabe registrar:

A escola deve integrar as tecnologias de informação e comunicação porque elas já estão presentes e influentes em todas as esferas da vida social, cabendo à escola, especialmente à escola pública, atuar no sentido de compensar as terríveis desigualdades sociais e regionais que o acesso desigual a estas máquinas está gerando.

Já existem várias pesquisas que apontam a importância da inserção das novas TICs na educação e de que maneira essa integração deve ocorrer. Destaca Cox (2003) quatro pontos fundamentais para que ocorra uma inserção mais adequada e eficaz das novas TICs na educação: "sensibilizar os agentes escolares; preparar o professor; 
Maria Aparecida Resende Ottoni e Flávia Motta de Paula

equipar a escola; e, ajustar o funcionamento das atividades escolares".

De acordo com Martinsi (2007), a utilização das novas TICs deve ser feita de maneira contextualizada, com atividades que façam parte da realidade dos discentes e que lhes permitam sentir-se partícipes do processo de ensino-aprendizagem:

Além dos recursos materiais e tecnológicos, a proposição de atividades deve buscar relacionar o que é ensinado na escola com as atuações dos alunos em determinados contextos. As atividades propostas devem desencadear situações que permitam a investigação, o estabelecimento e o compartilhamento de idéias entre o grupo, deixando vir à tona seus cotidianos e suas impressões sobre o mundo.

(MARTINSI, 2007, p. 1)

Diante desse cenário em constantes transformações, a escola é uma instituição onde todos os aspectos da sociedade são refletidos e, portanto, a escola também deve estar atenta à inserção das novas TICs, procurando integrá-las de forma criativa e profícua, de modo que professores e alunos se sintam aptos a utilizar essas novas ferramentas e a se beneficiar delas.

\section{Análise de dados}

Nesta seção, apresentamos a análise do texto da mídia impressa e das entrevistas com as professoras de Língua Portuguesa conforme arcabouço teórico - metodológico da Análise de Discurso Crítica (ADC) na vertente fairclougheana.

\subsection{Análise da reportagem da revista Nova Escola}

Em "A tecnologia que ajuda a ensinar", são apresentados alguns exemplos (meios e ferramentas) de como utilizar as tecnologias de informação e comunicação da educação. Para isso, a Revista Nova Escola selecionou 17 especialistas, dividindo-os por disciplinas, para 
construírem diferentes modelos de uso dessas novas ferramentas digitais; porém, vou me ater somente ao texto introdutório e à parte da Língua Portuguesa, em função do escopo dessa pesquisa.

Ao longo da reportagem, percebemos que existe uma representação positiva da inserção das TICs nas salas de aula. Essa representação é tecida por meio do diálogo do discurso da jornalista com outros discursos da esfera da educação e do governo. Semelhante à reportagem 01, os discursos aqui também são articulados e empregados no discurso da mídia por meio da intertextualidade explícita, expressa por meio da citação de falas da coordenadora pedagógica da própria revista, da coordenadora da área de inovação educativa da Organização dos Estados Ibero-Americanos para a Educação, a Ciência e a Cultura $(\mathrm{OEI})^{5}$ e do assessor da prefeitura de São Paulo.

Todos esses discursos são trazidos para a reportagem como uma forma de estabelecer uma representação discursiva positiva da inserção das novas TICs nas escolas, como poderemos observar pelas análises das escolhas lexicais presentes nesses discursos. Amanda Polato, jornalista da Nova Escola, apresenta muitas vantagens de se utilizar as TICs, dentre elas: que a internet é uma fonte de múltiplas informações; que as TICs ajudam-nos a enfrentar desafios atuais; que softwares podem auxiliar no trabalho com a correção ortográfica; e, ainda, que as novas TICs são indispensáveis para uma educação de qualidade. Todos esses argumentos reforçam uma posição positiva em relação à inserção das novas TICs na educação.

Além disso, é importante destacar que ela chama a atenção para a necessidade de articulação do uso das TICs com o conteúdo, "só vale levar a tecnologia para a classe se ela estiver a serviço dos conteúdos" e ainda para o fato de que em alguns casos é desnecessária sua utilização: "Em outros casos, porém, ela é dispensável. Não faz

5. A Organização dos Estados Ibero-americanos para a Educação, a Ciência e a Cultura (OEI) é um organismo internacional de caráter governamental para a cooperação entre os países ibero-americanos no campo da educação, da ciência, da tecnologia e da cultura no contato do desenvolvimento integral, da democracia e da integração regional. (fonte: www.oeibrpt.org. Acesso em 21/04/2010). 
sentido, por exemplo, ver o crescimento de uma semente numa animação se podemos ter experiência real”.

A jornalista ainda aponta para outro dado interessante, ela reconhece que a inserção das TICs pode ter provocado uma crise identitária nos professores e pode ter provocado diferentes reações neles: "Entre os professores, a disseminação de computadores, internet, celulares, câmeras digitais, e-mails, mensagens instantâneas, banda larga e uma infinidade de engenhocas da modernidade provoca reações adversas". No entanto, Amanda procura confortar os professores que possam estar inseguros: "Por ser relativamente nova, a relação entre a tecnologia e a escola ainda é bastante confusa e conflituosa”. Esse "conforto" pode ser interpretado como uma estratégia argumentativa que produz o efeito de adesão do leitor à tese defendida pela jornalista. Essa tese diz respeito a uma defesa da inserção das TICs na educação e, consequentemente, a uma representação positiva dessa inserção.

No discurso da mídia, representado pela voz da jornalista Amanda Polato, podemos identificar várias escolhas lexicais que contribuem para a construção dessa representação, como se pode ver a seguir:

(1) “TICs, tecnologia de informação e comunicação. Cada vez mais, parece impossível imaginar a vida sem essas letrinhas".

(2) "Por ser relativamente nova, a relação entre a tecnologia e a escola ainda é bastante confusa e conflituosa. NOVA ESCOLA quer ajudar a pôr ordem na bagunça buscando respostas a duas questões cruciais. A primeira delas: quando usar a tecnologia na sala de aula? A segunda: como utilizar esses novos recursos?"

(3) "Juntos, teoria, cinco casos reais e oito planos de aula (três na revista e cinco no site) ajudam a mostrar quando - e como - computadores, internet, celulares e companhia são fundamentais para aprender mais e melhor”. 
(4) "A informática também pode ajudar no trabalho com gêneros textuais".

(5) "Nesse sentido, blogs, fotologs e podsasts são novos gêneros, com características próprias. (...) Cada vez mais, a turma vai precisar conhecer esses aspectos”.

No fragmento (1), Amanda Polato utiliza o verbo no presente do indicativo "parece" e o adjetivo "impossível", o que Fairclough (trad. 2001, p.201) apresenta como uma declaração avaliativa, em que a jornalista expressa um juízo de valor do que é indispensável, o que denota uma dependência do homem em relação às TICs no mundo atual. Essa relação de dependência apresenta-se como crescente por meio da utilização da expressão adverbial "cada vez mais". Além disso, o verbo "parece" é um verbo modalizador epistêmico, denotando um alto grau de comprometimento e afinidade da jornalista com a proposição. Essa característica é denominada por Fairclough (trad. 2001, p. 200) como uma modalidade subjetiva, em que Polato deixa clara sua posição favorável à inserção das TICs.

No fragmento (2), a jornalista representa a relação entre a tecnologia e a escola como ainda bastante confusa e conflituosa. Isso contribui para uma identificação com o discurso da autora, por parte dos professores que ainda não lidam bem com a tecnologia e provoca uma adesão desse leitor ao discurso da mídia. Nesse mesmo fragmento, Polato utiliza a expressão "pôr ordem na bagunça", o que deixa claro que a revista identifica que é necessária uma organização na relação professor/novas TICs. Pelas escolhas lexicais de Amanda, com o uso do substantivo feminino "bagunça", percebemos que ela faz uma avaliação negativa da situação entre professores e as TICs, mostrando que é necessário colocar ordem na mesma. Ainda neste trecho, Amanda faz uso do adjetivo "bastante", que de acordo com Fairclough (trad. 2001) é um elemento avaliativo, em que autora expressa um juízo de valor, intensificando que a relação da escola com as TICs é desorganizada.

Além disso, Polato utilizou a locução verbal "quer ajudar", para mostrar que a revista se importa com essa relação conflituosa e tem o 
intuito de colaborar com os docentes, assumindo uma postura solidária com os professores e se colocando à disposição para auxiliá-los. Ainda no fragmento (2), são apresentadas duas perguntas que têm sido repetidas por muitos educadores e pesquisadores da área e o fato de a jornalista dizer que vai buscar respostas a elas contribui para atrair a atenção dos docentes para o texto, pois eles querem muito obter tais respostas.

No fragmento (3), Amanda Polato, por meio da expressão "são fundamentais para aprender mais e melhor", deixa clara a posição favorável à inserção das TICs nas escolas. O adjetivo "fundamental" e os advérbios de intensidade "melhor" e "mais" pressupõem algo essencial, bom, desejável, o que remete a uma declaração avaliativa, mostrando um alto grau de comprometimento da jornalista com suas afirmações. Porém, é importante destacar o uso das conjunções "quando" e "como", que são marcas de que não se defende o uso das TICs em qualquer aula e de qualquer maneira. Isso também é enfatizado nos seguintes dizeres: "só vale levar a tecnologia para a classe se ela estiver a serviço dos conteúdos"; "Mas é preciso avaliar se as oportunidades são significativas".

Essas afirmações são importantes porque trazem um pressuposto de que não se deve usar as TICs somente para dizer que as está usando porque dizem que isso é bom e necessário, mas, sim, utilizá-las com propósitos definidos e para propiciar mais qualidade ao processo de ensino e aprendizagem.

No fragmento (4), a jornalista também faz referência a um termo que ganhou destaque no ensino de Língua Portuguesa, especialmente após a publicação dos PCN: os gêneros textuais. Ao afirmar que a tecnologia - informática - pode auxiliar no trabalho com os gêneros, a autora procura também obter a adesão dos professores, uma vez que muitos deles estão em busca de caminhos para realmente ensinar a língua por meio dos gêneros, como proposto nos PCN.

E, no fragmento (5), ela se refere a novos gêneros em emergência, em decorrência dos avanços tecnológicos, e afirma a necessidade de os alunos conhecerem as especificidades desses novos gêneros: "cada vez mais, a turma vai precisar conhecer esses aspectos”. A expressão adverbial "cada vez mais", como afirmado anteriormente, denota que a necessidade de conhecimento desses aspectos é crescente e contínua. 
Além disso, nesse trecho podemos observar uma declaração de obrigação, o que Fairclough (2001) classifica como modalidade deôntica, pois, utilizando a locução verbal "vai precisar", a jornalista quer destacar e impor o que ela acredita ser uma boa coisa a ser realizada. E ainda, por meio desse trecho, podemos destacar uma modalidade categórica, já que a locução "vai precisar" tem valor de futuro do presente do indicativo, o que demonstra que a jornalista se compromete de maneira direta com sua afirmação e deixa clara sua posição em relação ao uso das TICs.

Para reforçar seus argumentos quanto ao uso da tecnologia para trabalhar com os novos gêneros, Polato demonstra exemplos de trabalhos realizados por dois professores. O primeiro, do professor de Língua Portuguesa Jorge Luiz Marques de Moraes, mostra que é possível conjugar o aprendizado de novos gêneros com conteúdos tradicionais. O foco de Moraes foi o gênero "podcast" 6 . A jornalista enfatiza que esse docente foi um dos ganhadores do Prêmio Victor Civita7 - Educador Nota 10 em 2008. Esse destaque constitui um argumento para comprovar a eficiência do trabalho realizado e da utilização das TICs no ensino de língua portuguesa.

O outro exemplo é o da professora Andressa Mille Fernandes que trabalhou com a produção de um informativo sobre o ciclo da água utilizando-se da informática. Com relação ao trabalho dessa professora, a jornalista também salienta que ele foi uma proposta interdisciplinar, viabilizada pelo uso das TICs:

(6) "propôs à turma do $4^{\circ}$ ano a construção de um informativo sobre o ciclo da água. um conteúdo que já havia sido tratado nas aulas de Ciências”.

6. Podcasting é uma forma de publicação de arquivos de mídia digital (áudio, vídeo,

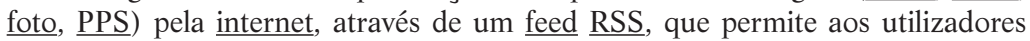
acompanhar a sua atualização. Com isso, é possível o acompanhamento e/ou download automático do conteúdo de um podcast.

7. O Prêmio Victor Civita - Educador Nota 10 é uma iniciativa da Fundação Victor Civita (FVC) que visa identificar, valorizar e divulgar experiências educativas de qualidade, planejadas e executadas por professores, diretores e coordenadores pedagógicos em escolas de ensino regular. (fonte: www.revistaescola.abril.com. br/premiovc, acesso em 21/04/2010). 
Neste fragmento, Polato aponta que a professora de Português utilizou o conteúdo do ciclo da água para fazer um informativo e esse conteúdo já havia sido trabalhado pelo professor de Ciências. Dessa maneira, Amanda utiliza o discurso pedagógico para abordar um tema muito discutido entre os educadores: a interdisciplinaridade. Vários estudos tentam promover essa relação entre as diferentes disciplinas, mas essa prática ainda não faz parte do cotidiano escolar de muitos docentes, como aponta Jesus (2006):

A interdisciplinaridade atualmente é a palavra de ordem para as novas propostas educacionais no Brasil e no mundo, porém a maioria dos educadores não sabem o que fazer com ela, sentindo-se amedrontados com a possibilidade de sua implementação no sistema educacional brasileiro. Nos novos projetos para o ensino visivelmente percebe-se a falta de segurança que faz parte do novo paradigma emergente do conhecimento (JESUS, 2006, p. 2).

A representação discursiva positiva da inserção das TICs no ensino de Língua Portuguesa construída no discurso da Nova Escola é reforçada pela inserção de outros discursos que funcionam como argumentos de autoridade dentro da reportagem, numa relação interdiscursiva. Esses discursos fazem parte das ordens de discurso pedagógico e governamental.

No que diz respeito ao discurso pedagógico, representado pela voz da coordenadora pedagógica da revista Nova Escola, Regina $\mathrm{Scarpa}^{8}$, podemos perceber algumas escolhas lexicais que cooperam para a construção dessa representação discursiva positiva da inserção das novas TICs nas escolas, como se pode ver a seguir:

(7) "Do ponto de vista do aprendizado, essas ferramentas devem colaborar para trabalhar conteúdos que muitas vezes nem poderiam ser ensinados sem elas".

8. Regina Scarpa é coordenadora pedagógica da Fundação Victor Civita e é Mestre em Educação pela USP. (Fonte:http://revistaescola.abril.com.br/fvc/quemsomos.shtml, acesso em 19/04/2010). 
No fragmento (7), Regina Scarpa utilizou o verbo auxiliar modal "devem", mostrando um alto grau de comprometimento com sua proposição, o que Fairclough (trad. 2001) classifica como uma modalidade categórica. Essa modalidade categórica utilizada pela coordenadora reforça que alguns conteúdos só poderiam ser ensinados com o uso das TICs. E ainda o verbo "colaborar" remete a uma avaliação, em que a coordenadora pedagógica constrói uma relação de colaboração em que as TICs são tidas como parceiras dos envolvidos no processo de ensino e aprendizagem e como capazes de agregar valores a esse processo.

Com relação ao discurso governamental, representado pela voz de Márcia Padilha Lotito, coordenadora da área de inovação educativa da Organização dos Estados Ibero-Americanos para a Educação, a Ciência e a Cultura (OEI), e pela voz de Cláudio Bazzoni, assessor da prefeitura de São Paulo, pode-se afirmar que também existe uma representação discursiva que apóia a utilização das TICs na educação:

(8) "A tecnologia tem um papel importante no desenvolvimento de habilidades para atuar no mundo de hoje".

"O professor pode deixar o corretor ortográfico ligado para que os estudantes tentem resolver, com autonomia, alguns erros - o que não o isenta de seguir ensinando ortografia”.

No fragmento (8), a coordenadora da área de inovação educativa da OEI utiliza o adjetivo "importante", que é um elemento avaliativo, apresentando um juízo de valor acerca da tecnologia. Ela faz referência a um aspecto que tem sido muito valorizado no campo da educação atualmente: o desenvolvimento de habilidades e de competências, mostrando que a tecnologia pode contribuir para isso. Além disso, o verbo "tem" no presente do indicativo realiza uma modalidade categórica, pois a jornalista se compromete com sua afirmação ao deixar claro o papel da tecnologia.

Os PCN também destacam a relevância do desenvolvimento de habilidades e competências dos alunos no mundo contemporâneo: 
O desenvolvimento de habilidades e o estímulo ao surgimento de novas aptidões tornam-se processos essenciais, na medida em que criam as condições necessárias para o enfrentamento das novas situações que se colocam. Privilegiar a aplicação da teoria na prática e enriquecer a vivência da ciência na tecnologia e destas no social passa a ter uma significação especial no desenvolvimento da sociedade contemporânea. (BRASIL, 1998, p.15).

Cláudio Bazzoni, no fragmento (9), apresenta-nos uma maneira de se utilizar o corretor ortográfico, o que para ele é uma ferramenta vantajosa, já que os alunos podem editar o que escrevem várias vezes. Além disso, o assessor da prefeitura de São Paulo traz para seu discurso um aspecto muito valorizado no discurso pedagógico atual: o desenvolvimento da autonomia do aluno. Atualmente, os profissionais da educação buscam formar discentes autônomos e críticos de suas realidades, como apontam os PCN (BRASIL, 1998, p. 83): "Cada aluno é sujeito de seu processo de aprendizagem, enquanto o professor é o mediador na interação dos alunos com os objetos de conhecimento". Nos PCN, a autonomia é definida como "capacidade a ser desenvolvida pelos alunos e como princípio didático geral, orientador das práticas pedagógicas” (BRASIL, 1998, p. 94). Ainda nesse fragmento, Bazzoni deixa clara a importância do professor, o qual deve continuar exercendo seu papel (no trecho, ensinar ortografia), mesmo com a inserção das TICs. Isso significa que as TICs não substituem os professores; elas são uma ferramenta de auxilio ao professor. Assim, no discurso de Cláudio Bazzoni, é construído o sentido de que as novas TICs trazem mudanças positivas, favorecendo a formação de estudantes autônomos.

Portanto, o que temos nessa reportagem é novamente o incentivo do uso das TICs na sala de aula, no entanto, de acordo com a revista Nova Escola, essa inserção deve se pautar nos conteúdos, em que tecnologia e conteúdos trabalharão em conjunto para propiciar uma educação "melhor", como aponta a jornalista Amanda Polato. Também é importante perceber que a revista tenta, de forma argumentativa, confortar o professor que tem dificuldades para lidar com as TICs, mas a todo momento insiste que ele deve trabalhar com as TICs. Assim, por meio das escolhas lexicais, da avaliação, da modalização e da interdiscursividade, notamos que existe 
uma representação discursiva positiva dessa inserção. Essa análise mostra o papel fundamental do vocabulário na caracterização dos discursos e, além disso, observamos diferentes discursos entrando em cooperação, deixando claro o processo de interdiscursividade.

\subsection{As docentes e o discurso sobre as TICs}

As entrevistas foram realizadas nas escolas onde as professoras trabalham e foram gravadas em áudio. É importante destacar que a escolha do local para entrevista foi feita pelas próprias docentes. Essas entrevistas foram transcritas sem preocupações com falas sobrepostas, entonações, silêncios, etc., porque o que nos interessava era apenas o conteúdo informacional. As transcrições encontram-se em anexo.

Foram realizadas entrevistas semiestruturadas, em conformidade com os pressupostos da pesquisa qualitativa (GEERTZ, 1978; BAUER \& GASKELL, 2002; LÜDKE \& ANDRÉ, 1986). A pesquisa de cunho qualitativo lida com descrições e interpretações da realidade social, a partir de dados interpretativos. Resende (2005, p. 112) destaca a relevância de uma pesquisa qualitativa:

Trata-se de uma forma de pesquisa potencialmente emancipatória, uma vez que por meio dela as ciências críticas podem identificar estruturas de poder naturalizadas em um contexto sócio-histórico definido. Por isso a pesquisa qualitativa é essencial quando se pretende focar representações de mundo, relações sociais, identidades, ideologias ligadas a um meio social.

De acordo com os princípios da entrevista semiestruturada, é mais viável apenas listar tópicos para direcionar o foco da pesquisa, e não fazer perguntas rígidas, pois este método pode engessar o entrevistado. Em nossas entrevistas, procuramos não fazer interferências, deixando os entrevistados livres para que pudessem expor suas opiniões em relação ao uso das TICs na educação. Desse modo, não fizemos todas as perguntas do roteiro a todos os entrevistados nem as fizemos na mesma ordem em que estão no roteiro. 
As entrevistas são analisadas de acordo com algumas categorias da Análise de Discurso Crítica. Para isso, tomamos como base dois dos três tipos de significados apresentados por Fairclough (2003): o significado representacional e o significado identificacional. $O$ primeiro relaciona-se com o conceito de discurso como modo de representação de aspectos do mundo, e o segundo, ao modo de ser, correspondente ao aspecto discursivo das identidades.

Esse recorte dos significados foi feito em função de objetivarmos investigar como as professoras representam discursivamente a inserção das TICs na educação e os efeitos dessa inserção na constituição identitária dessas docentes.

Com relação ao significado representacional, focaremos na análise do vocabulário e, no que diz respeito ao significado identificacional, na avaliação. Acreditamos que, por meio da análise do vocabulário utilizado pelas professoras nas entrevistas e por meio da análise dos recursos linguísticos usados para a avaliação, conseguiremos atingir nossos objetivos. Acreditamos, ainda, que as categorias dos dois significados estão inter-relacionadas, uma vez que há uma relação dialética entre eles.

\subsection{Como representam discursivamente a inserção das TICs na educação}

Segundo Fairclough (2003, p. 129), a identificação de um discurso em um texto envolve: identificar as principais partes do mundo que são representadas (os 'temas' centrais), e identificar a perspectiva, ou ângulo, ou ponto de vista particular de qual elas são representadas. Ao longo das entrevistas, percebemos como as professoras representam discursivamente a inserção das TICs na educação:

(1) Pesquisadora: E a senhora tem o costume de utilizar, a senhora tem acesso fácil na escola?

P19: É. O único problema é que pelo tamanho da escola, eu acho poderia ter mais computadores, né. Ou senão, outras salas para no

9. P1, P2 e P3 é como foram designadas as professoras participantes da pesquisa. 
mesmo horário duas salas usarem o laboratório. Que aí dava pra dar mais ênfase, né. Eles gostam. Eles gostam. Quando eles vão pra aula de informática, eu acredito que eles se empenham mais.

Pesquisadora: Então assim, a senhora acha que é importante essa inserção?

P1: Sim, com certeza. Isso ajuda, porque faz parte da realidade deles. Então, eu acredito que eles são estudantes virtuais, eles são filhos da internet. Eles são da geração da internet.

Pesquisadora: A senhora tem algum receio de ser substituída pela máquina?

P1: Não. Eu não acredito. Eu acredito assim, que a máquina ajuda bastante. A gente tem que dá uma nivelada. Nunca também só dá aula digitalizada. Mas é muito bom porque primeiro a gente tem que tentar pegar a atenção deles. (...) Então a gente tem que deixar o que eles gostam, tanto nós professores quanto os demais profissionais da escola. E tem determinados tópicos da língua portuguesa que eles não gostam tanto, então, se você não tiver um quadrinho, um desenho, alguma coisa para melhorar aquilo, eles não conseguem aprender o conteúdo.

(2) Pesquisadora: E a senhora acha válido, por exemplo, se a senhora tivesse a oportunidade de ter mais sala de laboratório?

P2: Seria excelente. Seria ótimo. Mas pra tudo, nós temos que contar com um fator que é essencial: o tempo de preparação. Nós não podemos levar os alunos pras salas de computadores e deixá-los a vontade. Nós temos que ter um tempo pra preparar essas aulas, mesmo na internet nós não podemos deixar o aluno chegar lá e pesquisar no site que ele quiser, como ele quiser. Tem que ser tudo preparado. E esse tempo infelizmente a gente não tem. Nosso tempo na escola é escasso. Nosso tempo em casa é escasso. A gente dobra, a gente tem dois turnos e a gente não tem tempo de fazer essa preparação. Seria ótimo, mas a gente não tem tempo.(...)

P2: (...) Pra gente ter mais tempo seria necessário trabalhar um turno só, mas pra trabalhar um turno só seria necessário ganhar melhor.

(...) 
P2: (...) o grande problema nosso é falta de tempo pra preparar melhor essas aulas. Nós não temos como chegar, no dia a dia e trabalhar com o computador, com a internet, com o data-show, sem essa preparação.

No fragmento (1), notamos que P1 representa a inserção das TICs como algo importante e que ajuda no processo de ensino e aprendizagem. E, com relação especificamente aos computadores, ela acredita que poderia haver mais desses equipamentos na escola, tanto porque os alunos gostam de usar essa ferramenta quanto porque ela os leva a se empenharem mais.

Na fala de P1, "poderia ter mais computadores", percebemos uma expressão de desejo de mudança, pois do jeito que está não é o ideal, nem satisfatório, o que também denota uma avaliação de P1 a respeito da inserção das TICs. Esse desejo também é identificado quando ela diz "[poderia ter] outras salas para no mesmo horário duas salas usarem o laboratório". Isso nos mostra que P1 epresenta discursivamente a inserção das TICs na educação como algo importante e que pode ainda ser melhor implementado na escola.

Quando questionada se tinha algum receio de ser substituída pela máquina, P1 respondeu de maneira categórica: "Não. Eu não acredito. Eu acredito assim, que a máquina ajuda bastante. A gente tem que dá uma nivelada. Nunca também só dá aula digitalizada”. Observamos que ela se coloca favorável à inserção das TICs, mas que entende que são apenas mediadoras no processo de ensino-aprendizagem. Ela utiliza os vocábulos "ajuda" e "bastante" para avaliar a máquina como útil e importante para auxiliar professor e alunos, durante as aulas.

P1 acredita que as TICs são artifícios para apreender a atenção dos alunos, os quais se mostram mais interessados quando estão no laboratório de informática. Porém, apesar da posição favorável ao uso dessas novas ferramentas, a docente explica que é necessário que os professores saibam usar as TICs de maneira equilibrada, sem deixar de desempenhar seu papel de educador. Nesse sentido, utiliza um discurso muito recorrente tanto na revista Nova Escola, quanto em pesquisas na área da educação, como se pode ver nos trechos a seguir: 
Usando a tecnologia como uma ferramenta para o aprendizado, adaptamos a prática docente aos novos tempos. A descentralização do conhecimento faz com que o nosso trabalho passe a ser mais o acompanhamento do desempenho dos estudantes e orientação para a melhoria da aprendizagem (PRATES, 2009, p. 16).

A interação professor - aluno vem se tornando muito mais dinâmica nos últimos anos. O professor tem deixado de ser um mero transmissor de conhecimentos para ser mais um orientador, um estimulador de todos os processos que levam os alunos a construírem seus conceitos, valores, atitudes e habilidades que lhes permitam crescer como pessoas, como cidadãos e futuros trabalhadores, desempenhando uma influência verdadeiramente construtiva (SANTOS, 2010, p. 5).

Em relação a P2, no fragmento (2), percebemos que a docente, ao utilizar a expressão "Seria excelente. Seria ótimo", avalia positivamente a possibilidade de ter mais laboratórios de informática na escola, o que mostra que, para ela, a inserção das TICs é algo bom. Porém, destaca que não bastaria apenas haver mais laboratórios. Seria fundamental que os professores tivessem tempo para preparar as aulas a serem ministradas nesses espaços. Dessa forma, ela evidencia que, na atual condição de trabalho dos professores, desenvolver atividades planejadas com as TICs, de forma adequada, não faz parte da realidade dos docentes. Ao dizer "Seria ótimo, mas a gente não tem tempo", ela contrapõe o ideal ao real e mostra como a estrutura acaba impedindo a ação. Mostra, ainda, que o contexto escolar na realidade ainda está bem distante do que é proposto tanto pelos PCN quanto pelo programa "Digitando o futuro".

\section{Considerações finais}

Observamos, nas análises, que as escolhas lexicais e as vozes trazidas para a reportagem contribuem para a construção de uma representação e avaliação positivas da inserção das novas TICs na educação e para a afirmação da necessidade dessa inserção. Contudo, 
no texto analisado, destaca-se a importância de haver uma articulação consciente do uso das TICs e do desenvolvimento dos conteúdos para que haja melhorias no processo de ensino/aprendizagem.

Também observamos que as vozes presentes no texto estabelecem entre si uma relação harmônica e que, tanto no discurso da mídia, representado pela voz da jornalista, quanto nos discursos que compõem a reportagem, a modalidade categórica está presente. Com esse recurso, há um reforço da posição favorável à inserção das novas TICs na educação e um comprometimento dos sujeitos com seus dizeres. Isso resulta em maior credibilidade no que está sendo dito e, consequentemente, em maior adesão por parte dos leitores. Além disso, percebemos o uso da modalidade objetiva no texto da revista, o que contribui para a legitimação da opinião favorável ao uso das novas TICs, como se todos compartilhassem dos mesmos pontos de vista.

De acordo com Fairclough (2001), o uso da modalidade objetiva em grande parte implica alguma forma de poder. E o uso dessa modalidade pela mídia, considerada como outro poder institucional - o "quarto poder"10, pode contribuir para a construção de uma representação discursiva inquestionável. Nessa perspectiva entendemos que a Nova Escola pode influenciar a opinião dos docentes acerca da inserção das novas TICs em sua prática docente, de modo que haja uma maior adesão desses leitores a essa nova prática.

Ao investigarmos como as entrevistadas representam discursivamente a inserção das TICs na educação, identificamos que P1 representa essa inserção como algo importante, que ajuda no processo de ensino e aprendizagem e que pode ainda ser melhor implementado na escola. P1 mostra-se favorável à inserção das TICs, mas entende que são apenas mediadoras no processo de ensinoaprendizagem. P1 acredita que as TICs são artifícios para prender a atenção dos alunos, os quais se mostram mais interessados quando estão no laboratório de informática. Porém, apesar da posição favorável ao uso dessas novas ferramentas, a docente explica que é necessário

10. O termo "quarto poder" foi cunhado pelo historiador Macaulay, no século XIX, para definir o papel da mídia dentro das sessões do parlamento na Inglaterra (BRIGGS \& BURKE, 2004). 
que os professores saibam usar as TICs de maneira equilibrada, sem deixar de desempenhar seu papel de educador.

Enfim, é possível notar que, apesar das diferentes propostas governamentais existentes e da representação positiva da inserção das novas TICs na educação, construída na e pela revista Nova Escola, as escolas ainda não estão preparadas para um uso profícuo das TICs, pois faltam, aos professores, capacitação, tempo para preparação de aulas, remuneração adequada e motivação. Falta ainda, em algumas escolas, estrutura adequada para atender às necessidades dos professores e dos alunos, no que diz respeito ao uso dessas tecnologias integradas aos conteúdos. Esses fatores são determinantes para que as TICs sejam colocadas em segundo plano ou nem sejam utilizadas.

Dessa forma, tem-se uma representação de um ideal - construído nos documentos oficiais e na revista analisada -, ainda muito distante do real - construído no discurso das entrevistadas. Acreditamos que, para aproximar os dois polos, é preciso, em primeiro lugar, repensar a formação de professores, valorizar a educação e os profissionais da educação em nosso país.

Enviado em: 10/04/2012

Aprovado em: 08/08/2012

cidottoni@gmail.com/ flaviamottapaula@gmail.com

\section{Referências bibliográficas}

BELLONI, Maria Luiza. O que é mídia-educação. Campinas, SP: Autores Associados, 2001. - (Coleção polêmicas do nosso tempo; 78).

COX, Kenia Kodel. Informática na Educação Escolar. Campinas, SP: Autores Associados, 2003. - (Coleção polêmicas do nosso tempo; 87).

FAIRCLOUGH, N.. Discurso e mudança social. Coord. trad., revisão e pref. à ed. bras. de Izabel Magalhães. Brasília: Editora Universidade de Brasília, 2001.

Analysing discourse: textual analysis for social research. Londres e Nova York: Routledge, 2003. 
HALLIDAY, M. A. K.. An introduction to functional grammar. 2 ed. Londres, Melbourne, Auckland: Edward Arnold, 1994.

. Language in a social perspective. In: COUPLAND, N. \& JAWORKSY, A. Sociolinguistics: A reader and course-book. Nova York: St. Martin's Press, 1997, p. 31-39.

HALLIDAY, M. A. K. \& HASAN, R. Language, context, and text: aspects of language in a social-semiotic perspective. 2 ed. Oxford: Oxford University Press, 1989.

MARTINSI, Maria Cecília. Situando o uso da mídia em contextos educacionais. Programa de formação continuada em mídias na educação. Disponível em: <http://webeduc.mec.gov.br/midiaseducacao/index6. html >. Acesso em 11 fev. 2010.

MERCADO, Luís P. Leopoldo. Integração de mídias nos espaços de aprendizagem. Instituto Nacional de Estudos e Pesquisas Educacionais Anísio Teixeira. Versão eletrônica ISSN 0104-1037. Disponível em: <http:// www.emaberto.inep.gov.br> Acesso em 20 nov 2010.

MONTEIRO. Elis. Nativos digitais já estão dominando o mundo e transformando a forma como o ser humano se comunica. Jornal O Globo, São Paulo, 18 maio 2009. Disponível em: <http://oglobo.globo.com/ tecnologia/mat/2009/05/18/nativos-digitais-ja-estao-dominando-mundotransformando-forma-como-ser-humano-se-comunica-755911408.asp > . Acesso em 13 jun 2010.

MORAN, José Manuel; MASETTO, Marcos; BEHRENS, Marilda. Novas tecnologias e mediação pedagógica. 3a edição, Campinas: Papirus, 2001.

OTTONI, M. A. R.. Os gêneros do humor no ensino da Língua Portuguesa: uma abordagem discursiva crítica. 2007. Tese (Doutorado em Linguística) Departamento de Linguística, Português e Línguas Clássicas, Universidade de Brasília, Brasília, 2007.

PINHEIRO, Tatiane. Tecnologia na aula. Nova Escola, São Paulo, n.228, p. 76-77, dez. 2009.

RESENDE, Viviane Melo \& RAMALHO, Viviane. Análise de discurso crítica. São Paulo: Contexto, 2006. 